\title{
Sobre a arte da \\ autorracionalização: fé e autoajuda no mercado de publicações ${ }^{1}$
}

\author{
leda Tucherman e Leandro de Paula Santos
}

\section{Resumo}

Baseado na análise de reportagens de revistas

brasileiras de popularização da ciência, o texto comenta a relação entre discursos que positivam a vivência da fé e o sucesso comercial das narrativas de autoajuda. Buscamos debater como se disseminam no mercado editorial novas imagens a respeito da relação entre espiritualidade e saúde, tematizando essa última como um valor normativo no modelo do capital contemporâneo. Nosso objetivo é, assim, esboçar linhas de contágio entre diferentes dimensões da experiência humana que passam a concorrer, no interior dos discursos analisados, como formas de resposta a expectativas do contexto político e econômico atual.

\section{Palavras-Chave}

Divulgação Científica. Fé. Espiritualidade. Autoajuda.

leda Tucherman I iedatucherman@gmail.com Doutora em Comunicação pela Universidade Federal do Rio de Janeiro, realizou seu pós-doutorado no Institut de Recherche en Acoustique et Musique. É professora do Programa de Pós-Graduação em Comunicação e Cultura e coordenadora do grupo de pesquisa "Imaginário Tecnológico" da Escola de Comunicação da UFRJ.

\section{Leandro de Paula Santos I psleandro@gmail.com} Doutorando em Comunicação e Cultura, sob orientação da Profa. leda Tucherman, e membro do grupo de pesquisa "Imaginário Tecnológico" na ECO/UFRJ. Cumpre estágio-sanduíche, com bolsa FAPERJ, no "Religion, Experience and Mind Lab Group" da Universidade da Califórnia, em Santa Barbara.

\section{Introdução}

Entre os anos 1970 e 1980, Zen e a arte de manutenção das motocicletas: uma investigação sobre valores, romance norteamericano escrito em 1974 por Robert Pirsig, transformou-se em um best-seller. Depois de ter sido recusado por alguns editores, 0 livro acabou vendendo mais de 5 milhões de exemplares em edições de línguas diferente ${ }^{2} \mathrm{e}$ sendo considerado um dos 10 lançamentos mais importantes da década pela Time Magazine.

0 livro relata os 17 dias de uma viagem de motocicleta feita por pai e filho, que são acompanhados no primeiro trecho por um casal de amigos, John e Sylvia, e seguem depois sozinhos, o garoto, Cris, na garupa do pai. Como indica o subtítulo, "uma investigação sobre os valores", a viagem é pontuada por inúmeras reflexões que reconhecemos pertencer ao campo da filosofia. 0 interesse que apresentam para o presente texto fica evidenciado por dois pequenos trechos; o primeiro é uma das epígrafes do livro: 
0 estudo da arte da manutenção das motocicletas é realmente um estudo em miniatura da arte da auto-racionalização. Reparando uma motocicleta trabalhando bem, com cuidado, tornamo-nos parte de um processo cujo fim é alcançar uma íntima paz de espírito. A motocicleta é principalmente um fenômeno mental. (PIRSIG, 1986, p.4)

0 segundo trecho é um diálogo entre pai e filho:

\footnotetext{
- "Você acredita em fantasmas?"

- "Não", respondo.

- "Por que não?"

- "Porque eles são anti-ci-en-tí-fi-cos."

(...)
}

- "Eles não contêm matéria" - continuo - "e nem energia; portanto, de acordo com as leis da ciência, só existem na cabeça da gente."

(..)

- "Naturalmente, as leis da ciência também não contêm matéria nem energia, e, portanto, também só existem na cabeça da gente. É melhor assumir uma atitude inteiramente científica $\mathrm{e}$ recusar-se a acreditar tanto nos fantasmas quanto nas leis da ciência. Assim, a gente não corre o perigo de errar. 0 único problema é que a gente fica sem ter muito em que acreditar, mas isto também é científico." (Ibid., p. 38)

Como se trata de um romance on the road, tão ao gosto da cultura norte-americana da época e de um autor filósofo, podemos deduzir que um dos valores que ele está questionando é o do crer, acreditar ou, como se diz em alguns rincões brasileiros, "botar fé". Vale ressaltar que a questão da crença é levantada como uma indagação; Pirsig não responde o que aconteceria se soubéssemos que há poucas coisas em que podemos, de fato, acreditar.
De algum modo, a situação descrita no diálogo anterior nos lembra que crer, seja em fantasmas ou mesmo nas leis da ciência, é uma natural exigência da condição humana: se conhecer parece ser o inelutável destino de nossa experiência como sujeitos, acreditar estaria na base de toda nossa possibilidade de ação. Muitos séculos antes, Santo Agostinho já havia definido, em seus Sermões, a indissociabilidade dessas duas operações ao afirmar ser preciso compreender para crer (intellige ut credas), mas igualmente necessário crer para compreender (crede ut intelligas), propondo a paridade entre dois termos cuja equação se mostraria, desde 0 início da era moderna, problemática frente ao paradigma do sujeito cognoscente.

É sobre o rearranjo das fronteiras entre conhecer e crer, refletido nas relações entre ciência e fé, que nosso texto objetiva refletir, sobretudo a partir de sua imbricação com os temas da saúde e do bem-estar, na forma como vem sendo visibilizada no mercado editorial brasileiro. No romance de Pirsig, a "íntima paz de espírito" poderia indicar o correlato de uma motocicleta em pleno funcionamento. Quatro décadas depois, sondamos onde e como estariam surgindo novas representações da tão almejada "arte da auto-racionalização".

Nos meses de novembro e dezembro de 2013, duas revistas brasileiras dedicadas à Encontro Anual da Compós, realizado na Universidade Federal do Pará, em Belém, entre 27 e 30 de maio de 2014. 
popularização da ciência ocuparam-se da relação entre saúde e espiritualidade em suas matérias de capa. A entrada do tema em cena por dois meses seguidos poderia não passar de coincidência; contudo, essa pauta vem assumindo notável regularidade em nosso mercado de publicações ${ }^{3}$, dando a ver a positivação da experiência da fé como ingrediente da boa administração do "fenômeno mental" contemporâneo.

0 interesse pela fé que comparece nessa tendência editorial não esconde seu caráter pragmático, vinculado a efeitos mensuráveis e imageticamente demonstráveis, como ilustram as figuras anteriores. A revista Super Interessante afirma que "fé faz bem" e que "é a ciência que está dizendo: quem crê em algo acima de si vive mais, ganha melhor e é mais feliz". Ainda em sua capa, oferece ao leitor uma síntese da nova roupagem da fé: "Saiba como se beneficiar disso, com religião ou sem".

A matéria aponta que, impulsionadas por estudos recentes, as principais faculdades de Medicina norte-americanas vêm incluindo em seus currículos oficiais ao menos uma disciplina exclusivamente dedicada às relações entre espiritualidade e saúde. Já a reportagem "Fé pode (mesmo) curar", da revista Saúde é Vital, comenta que a anamnese espiritual é uma prática clínica que ganha cada vez mais espaço também em prontos-socorros, UTIs e salas de cirurgia no Brasil. A reconstituição da trajetória

Figuras 1 e 2: Capas das edições de novembro e dezembro de 2013 das revistas Super Interessante e Saúde é Vital.
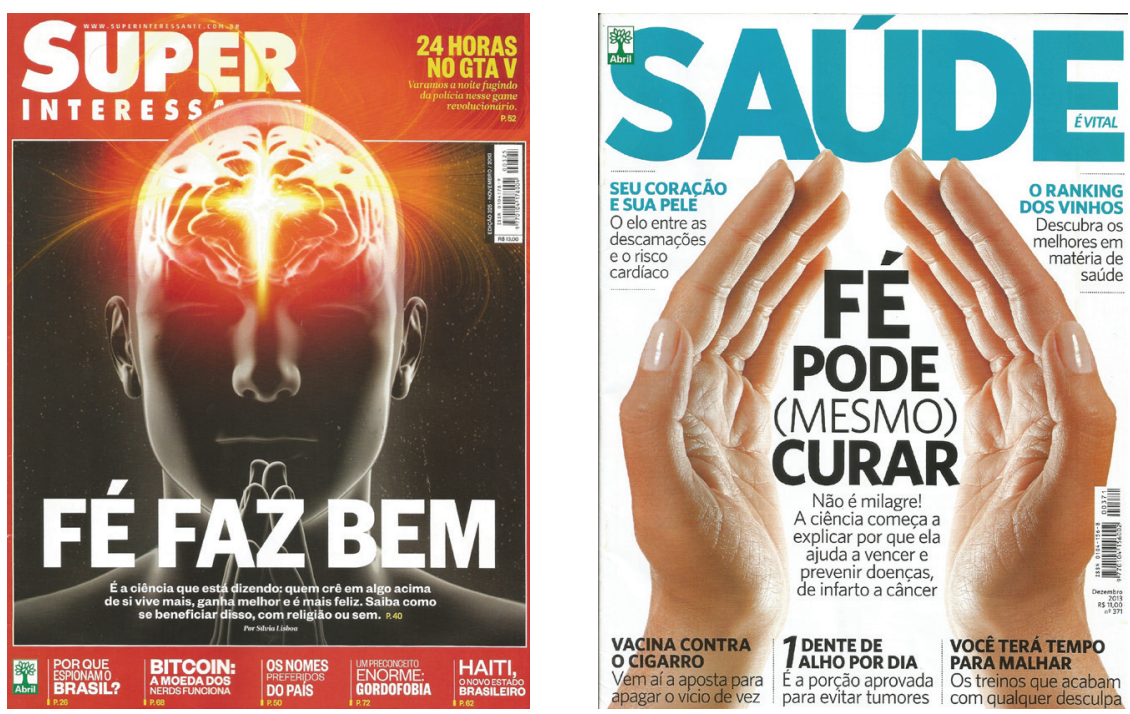

Fonte: [Fig. 1] Super Interessante. Ed. Abril, nº 325. Novembro de 2013. [Fig. 2] Saúde é Vital. Ed. Abril, nº 371. Dezembro de 2013.

Cf., por exemplo, as matérias "Divino cérebro" e "Milagres contemporâneos", de 25 de junho de 2010, da revista IstoÉ; "Não importa qual a religião, o importante é praticá-la", publicada em 23 de março de 2009, e "Como a fé me ajudou a superar a depressão", de 08 de junho de 2013, ambas da revista Época. 
religiosa do paciente e a investigação do papel da fé em sua vida têm se tornado elementos fundamentais para a compreensão de seu quadro e a determinação de sua maneira de lidar com a doença.

Essa é a tônica do coping espiritual, uma forma de enfrentar adversidades a partir de esforços cognitivos, dentre os quais a fé tem papel de destaque. 0 coping vem se transformando em uma ferramenta bem cotada por médicos e terapeutas para reabilitar o paciente ou mesmo evitar patologias, que se estendem dos riscos cardíacos à insuficiência renal.

A criação do Programa de Saúde, Espiritualidade e Religiosidade, no Instituto de Psiquiatria da Universidade de São Paulo (USP), e do Grupo de Estudos em Espiritualidade e Medicina Cardiovascular, pela Sociedade Brasileira de Cardiologia, dá indícios da importância que o tema alcança na realidade das ciências médicas no país. "Já não faltam estudos demonstrando que a crença em algo transcendente - Deus ou um poder superior interfere de forma positiva na capacidade de 0 corpo humano enfrentar doenças e até escapar delas", diz a matéria da revista Saúde é Vital. 0 psicólogo Kenneth Pargament, referência na prática do coping espiritual, por exemplo, defende a ideia de uma santificação ateísta, ou seja, a sacralização de um aspecto da vida como uma forma de se atingir artificialmente as benesses da fé. 0 que é preciso, afirma a Super Interessante, é simplesmente ter uma forte crença em algo.
Mas em que aspecto esses enunciados chamam a atenção? Ao menos desde Hipócrates e os gregos, sabemos existir uma relação entre estados de humor e doenças: a "bílis negra", tristeza, acompanhava-se de um enfraquecimento, e por isso era preciso evitá-la e combatê-la. Já segundo a milenar medicina oriental, o corpo é dotado da habilidade de detectar os desequilíbrios que lhe acometem e redirecionar as energias do indivíduo para promover um processo de cura de si mesmo. Para ambas as tradições culturais, portanto, morrer por falta de vontade de viver parece ser um fato conhecido há muito.

No entanto, vemos surgir nas matérias em análise um outro tipo de olhar sobre a relação entre corpo e espírito. Essas reportagens e os estudos em que se baseiam encontram seu ponto comum no que chamamos de biologização do social ou fisicalização das emoções, a partir da assunção do corpo não como meio, mas como mobilizador das mais distintas expressões da experiência humana.

Nesse sentido, a fé, como abstratamente descrita pelos dois artigos, funcionaria como uma pedagogia dos afetos, uma linha mestra de disciplinamento da conduta individual. Se há religiões com doutrinas e credos diferentes, a chamada espiritualidade seria potencialmente universal e estrategicamente benéfica para todo e qualquer um, tanto no controle das doenças como na sua prevenção. Essa noção é evidenciada pela revista Saúde é Vital quando ensina a seu leitor que: 
ser espiritualizado não significa necessariamente seguir uma religião. É, antes de mais nada, acreditar em alguma coisa intangível e que pode estar dentro de você - como a esperança de que, fazendo o bem, a gente é naturalmente recompensado. (p. 25)

0 jeito próprio como cada um pode constituir sua experiência espiritual, em detrimento da adesão a uma prática religiosa institucionalizada, aparece como um dos fatores mais festejados em revistas de variedades e de popularização da ciência que se dedicam a positivar a fé no atual cenário brasileiro ${ }^{4}$.

No ensaio Diálogo entre as culturas: do universal ao multiculturalismo, Julien (2010) discute modos com que, em nosso contexto de conexões e influências globais, culturas de diferentes matizes tendem a se encontrar e afrontar. Para tanto, 0 autor relê alguns dos fundamentos da história do pensamento ocidental e se vale de uma crítica à categoria do universal, apontando para sua tirania: o pressuposto de uma totalidade, no que tange à tematização dos fenômenos humanos, só poderia corresponder, na verdade, à arrogância de uma cultura frente outra que pretende dominar.

Como sabemos, a premissa da existência de uma universalidade prestou-se, no decorrer da História, a diferentes projetos de dominação cultural, dentre eles os de motivação religiosa. 0s movimentos de evangelização de povos colonizados são um capítulo conhecido dessa "arrogância" de que nos fala Julien, tendo constrangido inúmeros símbolos e práticas culturais, os quais foram ou propriamente dizimados ou relegados à condição de expressões marginalizadas social e politicamente.

Entretanto, como sugerem as publicações que aqui examinamos, talvez possamos estar assistindo ao surgimento de uma outra modulação da "universalidade", no que diz respeito à leitura dos fenômenos do espírito. Em lugar do predomínio de uma cosmologia religiosa - centrada em narrativas, ideias, ritos e/ou comunidades de pertencimento -, abre-se espaço para 0 elogio a uma forma de fé moldada a feitio de cada indivíduo: uma espiritualidade da qual estaríamos todos irremediavelmente dotados e que se disponibilizaria na vida cotidiana como um tipo de exercício.

No interior desta literatura que analisamos, 0 ponto de ancoragem que torna a fé um dado universal não parece estar na comunhão de um sentido unívoco para ideias como Deus, existência ou morte, sobre as quais as tradições teológicas longamente se ocuparam. Seu argumento de autoridade se encontra no papel dado ao corpo na vivência da fé, bem como na representação pública da ciência como repositório último de conteúdos verdadeiros, capaz de fornecer uma espécie de 
compensação ontológica para uma experiência fragmentada e desencantada.

Baseados em François Jacob (1991), vencedor do Prêmio Nobel de Fisiologia/Medicina em 1965, pensamos que essa crença no discurso da ciência é um dos fatores que a aproximam das narrativas mitológicas. Jacob propõe uma comparação entre a função e o modo de operação dos mitos e das ciências, escolhendo não o caminho do senso comum - que opõe tais domínios -, mas, ao contrário, buscando explorar seus tangenciamentos e continuidades.

Começando pelo objetivo, que seria o de encontrar uma ordem inabalável no caos do mundo, o mesmo princípio guiaria os mitos e as teorias científicas. Ele consistiria em explicar o mundo visível por forças invisíveis, articular o que se observa com o que se imagina. Explicar um fenômeno é, no limite, encontrar para um efeito visível uma causa escondida ligada às forças invisíveis que regem o mundo. Assim, a investigação científica teria como ponto de partida uma imaginação que inventa um mundo possível ou uma parte deste. Tal vizinhança entre o modelo de funcionamento da ciência e das narrativas mitológicas esboçada por Jacob indica que não se trata de dois domínios que se excluem ou invalidam, mas, antes, de duas fontes de produção de sentido que tendem a preponderar de acordo com sua conveniência a determinado quadro social e histórico.
Ninguém pesquisa no ramo das ciências da vida para si mesmo, assim como ninguém pesquisa - especialmente hoje, quando a tecnologia refinou-se tanto e aumentou exponencialmente as demandas de capital investido - fora de um projeto político. Ao eleger hoje a fé como um objeto privilegiado de tematização, certa produção discursiva da ciência popular parece andar a par e passo com narrativas modelares do atual "mercado" de scripts de subjetivação, revelando traços do projeto de poder que lhe engloba.

Tal literatura de divulgação científica guarda um evidente parentesco com os textos de autoajuda, copiando inclusive seu estilo, como podemos conferir em um livro citado na matéria da Super Interessante e indicado como leitura complementar. A abertura de 12 passos para uma vida de compaixãa, de Karen Armstrong (2012), assegura que:

Todos os doze passos serão educativos no sentido mais profundo da palavra; o latim educere significa "fazer sair" e este programa foi concebido para fazer aflorar a compaixão que, como vimos, existe em todo ser humano e pode tornar-se uma força benéfica em nossa vida $\mathrm{e}$ em nosso mundo (p. 25)

Assumindo a função de aconselhamento sobre os bons hábitos a se adotar no cotidiano, livros como 0 de Armstrong ${ }^{5}$ e as matérias em análise se estruturam de modo a atender a determinada vocação contemporânea. Na reportagem da Saúde 
é Vital, afirma-se que "mesmo se o indivíduo não estiver enfermo, seria bem-vindo exercer a caridade e 0 altruísmo". 0 curioso reaparecimento do elogio a virtudes como a compaixão - um legado, afinal, tipicamente religioso - sinaliza que os discursos com potencial normativo hoje operam sob um novo código moral: a saúde.

Esse valor máximo, capaz de prescrever ou desautorizar os comportamentos possíveis, pode ser entendido em sua relação com o ideal de autonomia que fundamenta o modelo do capital e enseja a contínua especulação sobre as formas de vida que lhe seriam correspondentes. É através dessa lógica de um bem-estar autoproporcionado que reconhecemos a articulação das novas abordagens da fé com o estilo retórico da autoajuda.

\section{Autoajuda como fenômeno comercial}

A visibilidade mais imediata do fenômeno da autoajuda é a quantidade de publicações que vem produzindo no mundo e também no Brasil, com tiragens surpreendentes. Além disso, essa tendência atinge outros gêneros literários, conquista parte da área do audiovisual ${ }^{6} \mathrm{e}$ gera comportamentos sociais como a moda da Cabala e a aproximação das religiões orientais, ambas ligadas a uma "demanda de espiritualidade".

Nossa premissa é de que esse sucesso se vincula à atualidade do capitalismo, na qual a tarefa do indivíduo é ser um empreendedor de si mesmo, necessitando desenvolver competências que valorizem seu capital biológico e abandonar hábitos que o depreciem. A autoajuda apresentase em torno de dois nichos de objetivos: 0 primeiro, ligado ao "alimento para a alma", em que a fé auxilia a encontrar equilíbrio, autoestima, autoconhecimento, bem-estar e felicidade; 0 segundo, de natureza totalmente pragmática, identificado por sucesso, dinheiro, prestígio, beleza e saúde. A autoajuda realiza, assim, uma insidiosa operação de marketing, uma narrativa motivacional para o indivíduo compatível com o biopoder.

Dois exemplos de êxitos comerciais deixam as aproximações que vemos entre 0 fenômeno da autoajuda e os discursos de divulgação científica sobre a fé mais claras, se nos permitirmos nomeá-los assim:

a) Você pode curar sua vida, publicado em 1984, por Louise Hay. Sua história é mais triste do que os mais tristes personagens da literatura, sejam os miseráveis de Victor Hugo ou as crianças injustiçadas de Dickens. Ela foi estuprada por um vizinho quando tinha 5 anos de idade. Sua mãe tentou levá-la à doação, no entanto, não conseguiu. Até os 15 anos, sofreu abusos sexuais, quando então saiu de casa para ser garçonete. Depois, sua vida melhora, ela se casa duas vezes e se torna guia de 
meditação transcendental. Neste momento, escreve um livro, Cure seu corpo, sobre um câncer do qual afirma que se curou com uma combinação de alimentação especial e técnicas mentais. Neste segundo livro, Você pode curar sua vida, a afirmação mais forte é de que as doenças são produtos do nosso estado de espírito e que, por isso, devemos romper com os pensamentos limitadores e trocar o medo pela fé.

b) A narrativa $O$ Segredo, de 2007, vendeu em um ano 2 milhões de DVDs e 6 milhões de livros impressos. Incluindo cientistas e intelectuais nas suas entrevistas, Rhonda Byrne, a autora, muniu-se de certo "verniz científico" para dar a seu "segredo" valor de verdade. 0 documentário pode ser resumido em uma palavra: Atração. A lei da atração é capaz de fazer qualquer coisa, bastando aplicá-la de modo incondicional para direcionar os pensamentos positivos e nunca desistir, ou seja, o segredo é ter uma "Fé Inabalável". Os três passos do comportamento seriam pedir, crer e receber. No limite, é o que o senso comum chama de manter um pensamento positivo, uma maneira como outra de falar de ter fé.

Esse receituário de autoajuda, verificado tanto em o Segredo como em Você pode curar sua vida, pode ser encontrado nas matérias que analisamos neste texto em sintonias sutilmente diferentes. As nuanças se colocam pelas linhas editoriais adotadas: enquanto a revista Saúde é Vital tem no próprio nome um indicativo de sua pauta primordial - a promoção de descobertas e hábitos indispensáveis para a otimização da saúde do leitor -, a Super Interessante caracteriza-se como um canal de divulgação de curiosidades culturais e científicas.

\section{A partir dessas predisposições, a Saúde é}

Vital (fig. 3) autentica a fé como prática essencialmente benéfica para 0 sistema nervoso, a imunidade e os processos de reabilitação do organismo, enfocando a existência de especialistas, universidades e centros de tratamento dedicados ao estudo da relação entre espiritualidade e saúde. Sua abordagem do tema pode ser resumida pela sentença que encerra a reportagem: "A fé não move montanhas, mas pode, sim, tirar doenças do nosso caminho".

Já a Super Interessante (fig. 4) abraça o estilo da autoajuda em uma visada mais pretensiosa, não restringindo os benefícios da fé à melhoria da saúde e à evitação de males, mas relacionando o cultivo da espiritualidade às exigências de uma vida de sucesso. Para ilustrar essa ideia, a reportagem menciona os descaminhos de um ícone da cultura pop: Homer Simpson, que faz pouco caso de qualquer fé, é obeso e alcóolatra. Seu antagonista é Ned Flanders, o vizinho carola, mas com saúde perfeita e corpo sarado.

A estereotipia faz parte do argumento da reportagem, que enumera as múltiplas vantagens 
Figura 3: Infográfico da matéria “0 remédio está na fé”, revista Saúde é Vital.

\section{FÉ DO LABORATÓRIO \\ Imagens cerebrais de freiras e monges budistas durante oração e meditação.}

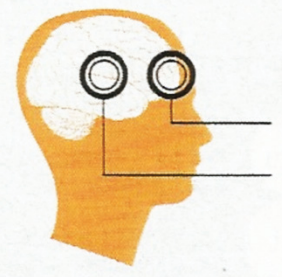

Duas áreas do cérebro ativadas: os lobos

frontais (parte responsável pela concentração) e 0

sistema limbioc

(relacionado às emoçōes)

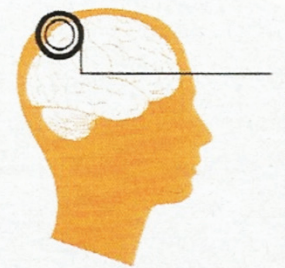

O lobo parietal, responsável pelo senso que temos de nós mesmos e do mundo, tem redução de atividade. Isso ajuda a explicar a sensação de perda de noção do tempo e do espaço ao meditar.
Fonte: "0 remédio está na fé". Revista Saúde é Vital, dezembro de 2013
Figura 4: Infográfico da matéria "A ciência da fé", revista Super Interessante.

Fonte: "A ciência da fé". Revista

Super Interessante, novembro de 2013.

a Super Interessante assegura ser possível desfrutar de todos os benefícios que os crentes usufruem mesmo sem se recorrer a qualquer transcendência. "Há ONGs", afirma, "que têm regras de conduta e convivência, reproduzindo os mesmos mecanismos das religióes que incentivam compaixão, autocontrole, senso de comunidade e comportamento ético."

Assim, favorecendo o exercício da espiritualidade, a opção por uma fé sem religião parece ter como compromisso dogmático expresso o bem-estar individual. E, a se medir pelas informações da Super Interessante, os resultados dessa escolha se estendem do aumento da renda média mensal à felicidade no casamento, passando pelas chances de se sobreviver a um transplante de fígado. 


\section{Fé e espaço público}

Confrontados com tais benesses da fé, somos tentados a enxergar os novos sentidos propostos no processo de publicização da ciência e reconhecer, no utilitarismo dessa espiritualidade promovida, um desdobramento do projeto neoliberal de governamentalidade. Essa literatura parece manifestar as vontades políticas que conduzem parte da pesquisa científica hoje, revelando, na própria vulgaridade de seus enunciados, os anseios que ordenam o mundo do capital.

Porém, essa produção discursiva é também sintoma de um movimento mais complexo, inscrevendo-se como desdobramento de uma epidemia de representações científicas que passaram a integrar o debate sobre a religião, em especial nos EUA e nos países anglófonos, desde 0 início dos anos 2000. Schneider (2008) defende que 0 processo de midiatização desses estudos vem seguindo a lógica geral de popularização de trabalhos científicos, a partir da transmutação de intrincados objetos e procedimentos de análise em pautas de comportamento acessíveis para amplas audiências.

Para diagnosticar essa tendência em nosso campo de análise, precisamos enquadrar as publicações que comentamos neste texto como amostragens de um mercado discursivo, espécie de bolsa de apostas editoriais orientada pela aceitação dos temas e abordagens oferecidos. À luz de Tarde (2005), entendemos que ambas as revistas publicadas pela editora Abril são produtos destinados a uma clientela sabidamente heterogênea, cuja unidade como "público leitor" é viabilizada somente pela sugestão editorial de cada veículo.

As tiragens das revistas dão conta desse universo em termos numéricos: Saúde é Vital imprime 210 mil exemplares ao mês; Super Interessante, 400 mil. Dadas a dimensão e a diversidade dessa clientela, pensamos que matérias como "A ciência da fé" ou "0 remédio está na fé" podem ser vistas não só como peças publicitárias sobre os comportamentos desejáveis em nosso tempo, mas quiçá também como possíveis respostas a expectativas de discussão latentes no cotidiano de seus leitores.

Noutras palavras, se é certo que essas reportagens procuram enquadrar a fé como um programa de benefícios, elas também alcançam o público médio por embalarem o tema da espiritualidade, em suas polivalentes acepções, como dimensão legítima de sua experiência subjetiva. A revista Saúde é Vital, por exemplo, chega a admitir que existe limite para o que a ciência pode explicar. Dentre os fenômenos espirituais que não se podem ainda descrever, estaria 0 efeito causado pelas orações à distância, como aquelas realizadas por parentes, e não por quem convalesce. Por enquanto, diz a publicação, apenas a física quântica é capaz de especular sobre esse auxílio que vem de fora e não é produzido pelo próprio paciente. 
A requalificação do tema da espiritualidade nos media brasileiros não aparece apenas nas revistas de divulgação científica. Uma das principais produções do canal Discovery Brasil no ano de 2013, o seriado Na Fé apresentou o jornalista Arthur Veríssimo participando de rituais místicos pela América Latina, do vodu do Haiti ao Círio de Nazaré em Belém, em busca de experiências que "despertam emoção e mexem com as crenças mais profundas de cada um" Adepto tanto do hinduísmo como do budismo tibetano, 0 apresentador confessou ${ }^{8}$ ter se sentido, em meio a transes como o banho de descarrego na festa de Iemanjá em Salvador, 0 próprio "James Bond da espiritualidade, o cara que realiza a missão impossível".

Já no GNT, o programa de entrevistas Viver com Fé busca apresentar, "mais do que a religião, a religiosidade que cada um carrega em si" ${ }^{\prime}$. A atração é comandada pela atriz Cissa Guimarães, "ecumênica, espiritualizada e sem preconceitos, uma pessoa de fé na vida", segundo suas próprias palavras ${ }^{10} .0$ sucesso do programa rendeu a publicação de um livro com o mesmo nome, dedicado a divulgar "histórias de quem acredita" e sintomaticamente classificado como um título de autoajuda.
Atendendo a uma demanda de debate e submetendo a fé e a espiritualidade a novos nexos, essa tendência vem apresentando nova roupagem para um antigo tema, em sintonia com o pendor tanto pragmático quanto cientificista da experiência contemporânea. Em alianças aparentemente fortuitas assim, entendemos abrirse um espaço de mediação social que influencia 0 campo das ações possíveis e forma 0 terreno para a construção de opiniões sobre um dado tópico.

Parece-nos, então, que os discursos produzidos sobre fé e espiritualidade, temas de delicado debate em um quadro histórico norteado pelas exigências do multiculturalismo e do materialismo tecnocientífico, podem revelar algo das lógicas conflitantes de nosso tempo. Nessas pautas que configuram certo painel da atualidade, as experiências de fé têm sido representadas segundo novos princípios de enunciação, que se estendem da religiosidade sem religião ao coping espiritual, dando a ver os vocabulários autorizados de nossa época.

\section{Considerações Finais}

0 que as leituras da fé perfiladas em nosso texto teriam, afinal, a indicar? Em primeiro lugar,

"Série 'Na Fé' mergulha em transes místicos coletivos", matéria de Silvana Arantes na Folha de S. Paulo, publicada em 17 de julho de 2013. Disponível em: http://www1.folha.uol.com.br/ilustrada/2013/07/1311857-serie-na-fe-mergulha-em-transesmisticos-coletivos.shtml. Acesso em 6 de dezembro de 2014.

Website do seriado Na fé. Disponível em: http://discoverybrasil.uol.com.br/web/na-fe/. Acesso em 6 de dezembro de 2014

Website do programa Viver com fé. Disponível em: http://gnt.globo.com/viver-com-fe/sobre/?. Acesso em 14 de janeiro de 2015.

10 Disponível em: http://gnt.globo.com/viver-com-fe/sobre/Cissa-Guimaraes.shtml. Acesso em 15 de janeiro de 2015. 
o que já sabemos: que nosso espaço público é atravessado por disputas de sentido, por constantes promoções e desqualificações dos mundos possíveis, pela existência de saberes e formas de veridicção em contínuo enfrentamento.

Também: que a prática discursiva sempre faz algo além de utilizar os signos disponíveis para representar uma realidade dada. Que o discurso é o que viabiliza 0 aparecimento de uma experiência histórica específica, o que organiza o caos dos enunciados sob a forma dos objetos reconhecidos e estipula as regras próprias de seu acontecimento.

Ainda: que 0 assíduo encontro entre ciência e fé como tópico de interesse editorial talvez revele um inusitado reposicionamento de olhares sobre a transcendência, aquele horizonte de experiência que continua a mover os indivíduos na direção do que lhes excede.

Ao destacarmos a repaginação da ideia de espiritualidade a partir de novos léxicos e a regularidade de sua entrada na mídia impressa, buscamos apontar 0 aparecimento de um modo de visibilização de práticas e crenças que, sendo acolhidas pela maioria da população brasileira ${ }^{11}$, vêm sendo colocadas em debate público sob 0 crivo da razoabilidade do discurso científico. Em tal movimento, evidencia-se um paradoxo: se assistimos à contaminação das abordagens da fé pelas terminologias da ciência, pelo estilo retórico da autoajuda e pela lógica do empreendimento de si, notamos também a reincidência do foco lançado àquele tipo de experiência que escapa a um modelo de explicação totalizante e cuja produção de sentido é inalienável ao sujeito.

Certo dualismo entre as ciências da natureza e as ciências humanas marcou o imaginário teórico dos últimos dois séculos, dando forma a um projeto de compreensão do homem que integrou a fantasia da modernidade e que, certamente, continua a direcionar a pesquisa científica hoje, inclusive na atenção que devota à fé. Contudo, a curiosa recolocação da espiritualidade como tema pode vir a indicar a obsolescência do diagrama descritivo da experiência subjetiva que, resultando desse mesmo dualismo, resiste a toda aspiração metafísica.

É dizer: o recente entrelaçamento de tópicos como fé e espiritualidade com 0 discurso científico, tal como operado por parcela do mercado editorial brasileiro, parece assumir uma função requalificadora, capaz de conferir aceitabilidade ao debate público de conteúdos apreendidos como inflexões da experiência privada de cada indivíduo. É, assim, como se a pauta requeresse a participação do glossário científico em seu tratamento, mas, ao mesmo tempo, apontasse os limites desse repertório frente ao que desafia a linguagem. $\mathrm{Ou}$, ainda, como se a 
crescente cientificização da experiência espiritual insinuasse, em um olhar mais cuidadoso, 0 contrário de sua aparência imediata: que "a crença cientificista em uma ciência que possa um dia não apenas complementar, mas substituir a autocompreensão pessoal por uma autodescrição objetivante não é ciência, é má filosofia" (HABERMAS, 2013, p. 13, grifo do autor).

Se a questão da transcendência vem sendo retomada como tema no interior de práticas discursivas nas quais a espiritualidade surge como expediente primordial para a construção de quem se é, tal acontecimento parece derivar também de novas leituras propostas sobre a natureza dos vínculos afetivos, tendo no amor seu objeto privilegiado de enfoque. Alguns autores complexificam essa ideia ao demonstrarem que tal sentimento teria ocupado o lugar de uma religião laica para um 0cidente de crescente ateísmo. Nesse sentido, as semelhanças entre a experiência da fé e do enamoramento têm sido constantemente comentadas: 0 amor se configuraria como uma das fontes de transcendência para o mundo contemporâneo ao possibilitar a constituição de novas unidades subjetivas. Simon May, um desses comentadores, define que, a exemplo do tipo de ancoragem que caracteriza as referências da fé, "0 amor é o enlevo que sentimos por pessoas e coisas que inspiram em nós uma fundação indestrutível para nossa vida" (MAY, 2011, p. 19).

A experiência de fundar um novo mundo a partir do outro parece corresponder àquele longínquo tipo de operação capaz de equacionar, para e no sujeito, os atos de conhecer e crer. Constituirse a partir de encontros com pares, com ideias, com deuses, sem submeter a transcendência ao utilitarismo de uma era: um gesto íntimo que representa uma vigorosa ação política hoje.

\section{Referências}

ARMSTRONG, Karen. 12 passos para uma vida de compaixão. São Paulo: Paralela, 2012.

HABERMAS, Jürgen. Fé e saber. São Paulo: Ed. UNESP, 2013.

JACOB, François. 0 jogo dos possíveis: ensaio sobre a diversidade do mundo vivo. Lisboa: Gradiva, 1991.

JULIEN, François. 0 Diálogo entre culturas: do universal ao multiculturalismo. Rio de Janeiro: Jorge Zahar, 2010.

LISBOA, Silvia. A ciência da fé. Super Interessante, São Paulo, v. 1, n 325, p. 40-49, novembro de 2013. MAY, Simon. Amor, uma história. Rio de Janeiro: Zahar Editores, 2011.

PIRSIG, Robert. Zen e a arte de manutenção das motocicletas: uma investigação sobre valores. São Paulo: Companhia das Letras, 1986.

SCHNEIDER, Nathan. What Happens To Religion When It Is Biologized? In: Science \& Spirit, v. 19, $\mathrm{n}^{0}$ 3. Maio/ Junho de 2008.

SPONCHIATO, Diogo et alli. 0 remédio está na fé. Saúde é Vital, São Paulo, v. 1, nº 371, p. 24-31, dez 2013.

TARDE, Gabriel. A opinião e as massas. São Paulo: Martins Fontes, 2005. 


\section{On the art of self-rationalization: faith and self-help in the publishing industry}

\section{Abstract}

Based on an analysis of popular science magazines, this paper intends to recognize the link between discourses that give the experience of faith a positive meaning and the commercial success of the self-help narratives. We aim to debate how the Brazilian publishing industry has been disseminating new representations of spirituality and health, and deal with this latter topic as a normative value within the capitalist framework. Thus, our purpose is to outline, in the examined discourses, the way different dimensions of the human experience play a key role in the emergence of responses to expectations of the current economic and political panorama.

\section{Keywords}

Scientific Disclosure. Faith. Spirituality. Self-Help.

\section{Acerca del arte de la racionalización de si: la fe y la autoayuda en el mercado de publicaciones}

\section{Resumen}

A través de un análisis de revistas de divulgación científica, el texto debate la relación entre los discursos que conceden a la experiencia de la fe un sentido positivo y el éxito comercial de las narrativas de autoayuda. Discutimos las imágenes editoriales acerca de la relación entre la espiritualidad y la salud, hecha un valor normativo en el capitalismo contemporáneo. Nuestro objetivo es, pues, sugerir las líneas de contagio entre diferentes dimensiones de la experiencia humana que empiezan a responder a expectativas del contexto político y económico actual.

\section{Palabras clave}

Divulgación Científica. Fe. Espiritualidad. Autoayuda. 


\section{Expediente}

A revista E-Compós é a publicação científica em formato eletrônico da Associação Nacional dos Programas de Pós-Graduação em Comunicação (Compós). Lançada em 2004, tem como principal finalidade difundir a produção acadêmica de pesquisadores da área de Comunicação, inseridos em instituições do Brasil e do exterior.

\section{E-COMPÓS I www.e-compos.org.br I E-ISSN 1808-2599}

Revista da Associação Nacional dos Programas de Pós-Graduação em Comunicação.

Brasília, v.18, n.1, jan./abri.. 2015.

A identificação das edições, a partir de 2008, passa a ser volume anual com três números.

\section{CONSELHO EDITORIAL}

Alexandre Rocha da Silva, Universidade Federal do Rio Grande do Sul, Brasil Alexandre Farbiarz, Universidade Federal Fluminense, Brasil Ana Carolina Damboriarena Escosteguy, Pontifícia Universidade Católica do Rio Grande do Sul, Brasil

Ana Carolina Rocha Pessôa Temer, Universidade Federal de Goiás, Brasil Ana Regina Barros Rego Leal, Universidade Federal do Piauí, Brasil André Luiz Martins Lemos, Universidade Federal da Bahia, Brasil Andrea França, Pontifícia Universidade Católica do Rio de Janeiro, Brasil Antonio Carlos Hohlfeldt, Pontifícia Universidade Católica do Rio Grande do Sul, Brasil

Arthur Ituassu, Pontifícia Universidade Católica do Rio de Janeiro, Brasil Álvaro Larangeira, Universidade Tuiuti do Paraná, Brasil Ângela Freire Prysthon, Universidade Federal de Pernambuco, Brasil César Geraldo Guimarães, Universidade Federal de Minas Gerais, Brasil Cláudio Novaes Pinto Coelho, Faculdade Cásper Líbero, Brasil Daisi Irmgard Vogel, Universidade Federal de Santa Catarina, Brasil Daniela Zanetti, Universidade Federal do Espírito Santo, Brasil Denize Correa Araujo, Universidade Tuiuti do Paraná, Brasil Eduardo Antonio de Jesus, Pontifícia Universidade Católica de Minas Gerais, Brasil

Eduardo Vicente, Universidade de São Paulo, Brasil

Elizabeth Moraes Gonçalves, Universidade Metodista de São Paulo, Brasil Erick Felinto de Oliveira, Universidade do Estado do Rio de Janeiro, Brasil Francisco Elinaldo Teixeira, Universidade Estadual de Campinas, Brasil Francisco Paulo Jamil Almeida Marques, Universidade Federal do Ceará, Brasil Gabriela Reinaldo, Universidade Federal do Ceará, Brasil Gisela Grangeiro da Silva Castro, Escola Superior de Propaganda e Marketing, Brasil

Goiamérico Felício Carneiro Santos, Universidade Federal de Goiás, Brasil Gustavo Daudt Fischer, Unisinos, Brasil

Herom Vargas, Universidade Municipal de São Caetano do Sul, Brasil
Itania Maria Mota Gomes, Universidade Federal da Bahia, Brasil Janice Caiafa, Universidade Federal do Rio de Janeiro, Brasil Jiani Adriana Bonin, Universidade do Vale do Rio dos Sinos, Brasil José Afonso da Silva Junior, Universidade Federal de Pernambuco, Brasil José Luiz Aidar Prado, Pontifícia Universidade Católica de São Paulo, Brasil Kati Caetano, Universidade Tuiuti do Paraná, Brasil

Lilian Cristina Monteiro França, Universidade Federal de Sergipe, Brasil Liziane Soares Guazina, Universidade de Brasília, Brasil Luíza Mônica Assis da Silva, Universidade de Caxias do Sul, Brasil Luciana Miranda Costa, Universidade Federal do Pará, Brasil Malena Segura Contrera, Universidade Paulista, Brasil Marcel Vieira Barreto Silva, Universidade Federal da Paraíba, Brasil Maria Ogécia Drigo, Universidade de Sorocaba, Brasil Maria Ataide Malcher, Universidade Federal do Pará, Brasil Maria Clotilde Perez Rodrigues, Universidade de São Paulo, Brasil Maria das Graças Pinto Coelho, Universidade Federal do Rio Grande do Norte, Brasil

Mauricio Ribeiro da Silva, Universidade Paulista, Brasil

Mauro de Souza Ventura, Universidade Estadual Paulista, Brasil Márcio Souza Gonçalves, Universidade do Estado do Rio de Janeiro, Brasil Micael Maiolino Herschmann, Universidade Federal do Rio de Janeiro, Brasil Mirna Feitoza Pereira, Universidade Federal do Amazonas, Brasil Nísia Martins Rosario, Universidade Federal do Rio Grande do Sul, Brasil Potiguara Mendes Silveira Jr, Universidade Federal de Juiz de Fora, Brasil Regiane Ribeiro, Universidade Federal do Paraná, Brasil Rogério Ferraraz, Universidade Anhembi Morumbi, Brasil Rose Melo Rocha, Escola Superior de Propaganda e Marketing, Brasil Rozinaldo Antonio Miani, Universidade Estadual de Londrina, Brasil Sérgio Luiz Gadini, Universidade Estadual de Ponta Grossa, Brasil Simone Maria Andrade Pereira de Sá, Universidade Federal Fluminense, Brasil Veneza Mayora Ronsini, Universidade Federal de Santa Maria, Brasil Walmir Albuquerque Barbosa, Universidade Federal do Amazonas, Brasil

\section{COMISSÃO EDITORIAL}

\section{Cristiane Freitas Gutfreind}

Pontifícia Universidade Católica do Rio Grande do Sul, Brasil

Irene Machado

Universidade de São Paulo, Brasil

Jorge Cardoso Filho

Universidade Federal do Reconcavo da Bahia, Brasil

Universidade Federal da Bahia, Brasil

$$
\begin{aligned}
& \text { REVISÃo DE TEXTOS I Press Revisão } \\
& \text { SECRETÁRIA EXECUTIVA I Helena Stigger } \\
& \text { EDITORAÇÃO ELETRÔNICA I Roka Estúdio }
\end{aligned}
$$

COMPÓS I www.compos.org.br

Associação Nacional dos Programas de Pós-Graduação em Comunicação

Presidente

\section{Eduardo Morettin}

Universidade de São Paulo, Brasil

eduardomorettin@usp.br

\section{Vice-presidente}

Inês Vitorino

Universidade Federal do Ceará, Brasil

ines@ufc.br

Secretária-Geral

Gislene da Silva

Universidade Federal de Santa Catarina, Brasil gislenedasilva@gmail.com 